\title{
Characterization of influenza outbreaks in Lebanon during the 2013/14 and 2014/15 seasons
}

R. Saito ', H. Akinobu ' , R. A. Shaker ${ }^{2}$, I. S. Akel ${ }^{2}$, A. Assaf-Casals ${ }^{2}$, M. Lteif' ${ }^{2}$, T. Odagiri ${ }^{1}$, R. Inaba ${ }^{1}$, N. Soudani ${ }^{3,4}$, S. Khafaja ${ }^{2}$, S. T. Ghanem ${ }^{5}$, M. Rajab ${ }^{5}$, Y. Shobugawa ${ }^{1}$, G. S. Dbaibo ${ }^{2,4,6}$, H. Zaraket . $^{3,4}$

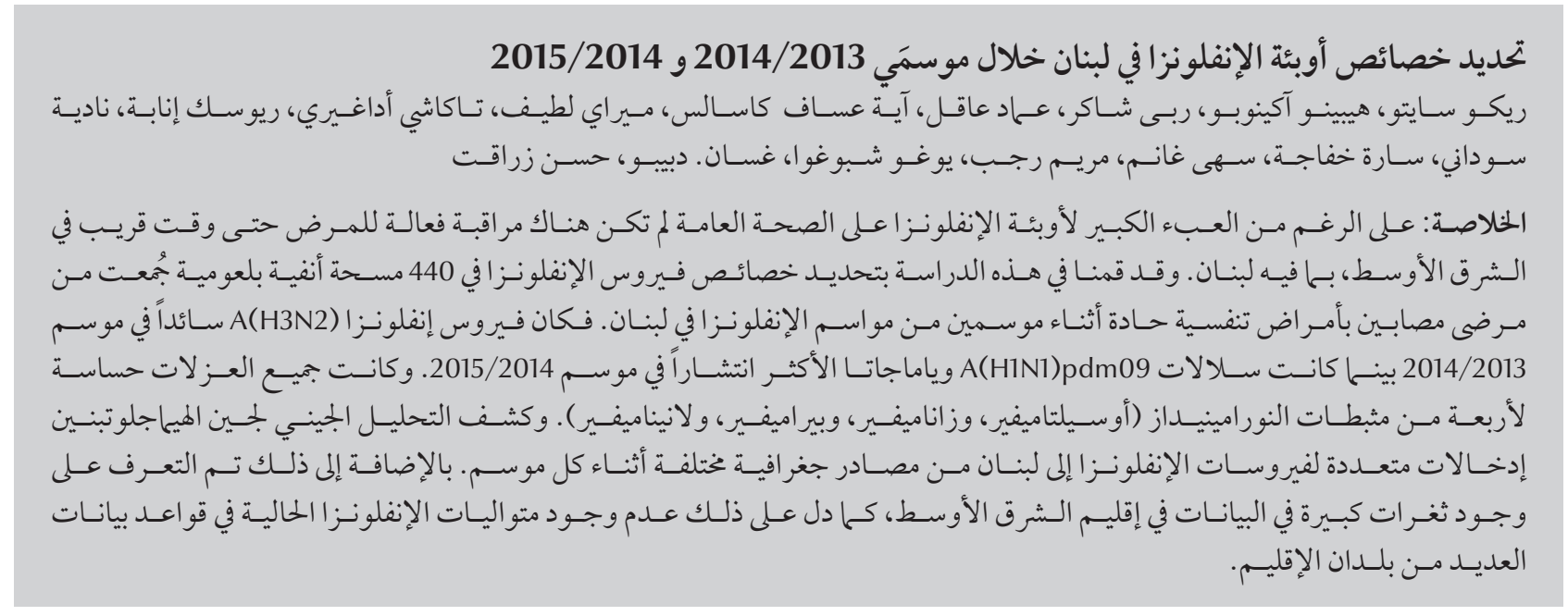

ABSTRACT Despite the significant burden of influenza outbreaks, active disease monitoring has been largely absent in the Middle East, including Lebanon. In this study we characterized influenza virus in 440 nasopharyngeal swabs collected from patients with acute respiratory infections during two influenza seasons in Lebanon. Influenza A(H3N2) was dominant in the 2013/14 season while the A(H1N1)pdm09 and B/Yamagata strains were most prevalent in the 2014/15 season. All tested isolates were susceptible to 4 neuraminidase inhibitors (oseltamivir, zanamivir, peramivir and laninamivir). Genetic analysis of the haemagglutinin gene revealed multiple introductions of influenza viruses into Lebanon from different geographic sources during each season. Additionally, large data gaps were identified in the Middle East region, as indicated by the lack of current influenza sequences in the database from many countries in the region.

\section{Caractérisation des flambées de grippe au Liban lors des saisons 2013/2014 et 2014/2015}

RÉSUMÉ Malgré la lourde charge que représentent les flambées de grippe, la surveillance active de la maladie était jusqu'à présent inexistante au Moyen-Orient, et notamment au Liban. Dans la présente étude, le virus de la grippe a été caractérisé dans 440 sécrétions rhinopharyngées prélevées par écouvillonnage chez des patients ayant souffert d'infections respiratoires aiguës pendant deux saisons grippales au Liban. Le virus de la grippe $A(H 3 N 2)$ était prédominant pendant la saison 2013/2014, tandis que celui de la grippe $\mathrm{A}(\mathrm{H} 1 \mathrm{~N} 1) \mathrm{pdm} 09$ et les souches de grippe B/Yamagata étaient les plus courants pendant la saison 2014/2015. Tous les isolats testés étaient sensibles à quatre inhibiteurs de la neuraminidase (I'oseltamivir, le zanamivir, le peramivir, et le laninamivir). L'analyse génétique du gène de l'hémagglutinine a révélé de multiples introductions des virus de la grippe au Liban, depuis différentes sources géographiques au cours de chaque saison. De plus, d'importantes lacunes dans les données ont été constatées dans la région du Moyen-Orient, comme le montre l'absence des séquences génétiques actuelles de la grippe dans les bases de données de nombreux pays de la région.

'Division of International Health, Graduate School of Medical and Dental Sciences, Niigata University, Niigata, Japan. ${ }^{2}$ Dept. Pediatrics and Adolescent Medicine (correspondence to: Ghassan Dbaibo: gdbaibo@aub.edu.lb; Hassan Zakarat: hz34@aub.edu.lb). ${ }^{3}$ Dept. Experimental Pathology, Immunology and Microbiology, Faculty of Medicine. ${ }^{4}$ Center for Infectious Diseases Research, Faculty of Medicine. ${ }^{6}$ Dept. Biochemistry, Faculty of Medicine, American University of Beirut, Beirut, Lebanon. ${ }^{5}$ Dept. Pediatrics, Makassed General Hospital Beirut, Lebanon.

Received: 28/04/16; accepted: 08/08/16 


\section{Introduction}

Influenza $A$ and $B$ viruses cause significant morbidity and mortality during their annual outbreaks (1). Two influenza A subtypes, $\mathrm{A}(\mathrm{H} 1 \mathrm{N1}) \mathrm{pdm} 09$ and $\mathrm{A}(\mathrm{H} 3 \mathrm{~N} 2)$, and 2 influenza $\mathrm{B}$ lineages, $\mathrm{B} /$ Yamagata and B/Victoria, circulate in humans $(2,3)$. Influenza A viruses are also associated with periodic pandemics that result in a significantly higher disease burden than annual outbreaks (4). Currently, neuraminidase inhibitors (e.g. oseltamivir) are the mainstay for treatment and prophylaxis of influenza infections (5). Maintaining the efficacy of these drugs and vaccines requires close monitoring of viruses circulating in the community on a global scale.

In this study, we genetically characterized influenza viruses that circulated in Lebanon during the 2013/14 and 2014/15 seasons. We also report their susceptibility to antiviral drugs.

\section{Methods}

Patients presenting with acute respiratory infections at 2 sentinel sites in Beirut, Lebanon were recruited to the study. The sentinel sites were Makassed General Hospital in Beirut and the American University of Beirut Medical Center, which together serve ethnically and socioeconomically varied patient populations. Two nasopharyngeal swabs were collected from each patient by a nurse or physician. We collected 444 swabs between July 2013 and June 2015, spanning the 2013/14 and 2014/15 seasons; 90 of these were collected during the 2013/14 season. One swab was tested immediately at the clinic or hospital using a rapidantigen detection test (RDT) (Quick Navi Flu+RSV, Denka Seiken, Japan). The second swab was suspended in viral transport medium and stored at $-80^{\circ} \mathrm{C}$ until shipped to the laboratory for further analysis. Subtype-specific real-time polymerase chain reaction (PCR) analysis was carried out on all samples testing positive by RDT. The PCR method used in this study employs cycling probes that can simultaneously detect the $\mathrm{H} 275 \mathrm{Y}$ mutation in the $\mathrm{A}(\mathrm{H} 1 \mathrm{~N} 1)$ pdm09 neuraminidase protein (6), which confers resistance to the neuraminidase inhibitors oseltamivir and peramivir. The phenotypic antiviral drug susceptibilities were determined for 9 isolates from the 2013/14 season and 17 from the 2014/15 season using a fluorescent-based neuraminidase inhibition assay $(7,8)$.
All patients consented to participate in the study, which was approved by the ethics committee at the American University of Beirut. The haemagglutinin (HA) genes of 24 influenza $A$ and $B$ isolates were sequenced as described in a previous study (9). Sequences were aligned in BioEdit 7.5.5 (10) and phylogenetic trees were inferred using maximum-likelihood method based on the best fit nucleotide substitution model with 1000 bootstrapped iterations implemented in MEGA 6.0 (11).

\section{Results}

Of the 90 samples that were collected during the 2013/14 season, 31 (34.4\%) were positive for influenza A and none for influenza B (Figure 1). Influenza activity peaked in January during the 2013/14 season but was delayed till March during the 2014/15 season. Analysis of all samples testing positive for influenza showed $6(19.3 \%)$ were $\mathrm{A}(\mathrm{H} 1 \mathrm{N1})$ pmd09, 16 (51.6\%) were $A(H 3 N 2)$, and $3(9.7 \%)$ were $\mathrm{A}(\mathrm{H} 1 \mathrm{~N} 1) \mathrm{pdm} 09$ and $\mathrm{A}(\mathrm{H} 3 \mathrm{~N} 2)$ mixed infections.

Of the 350 swabs collected during the 2014/15 season, 51 (14.5\%) were influenza $\mathrm{A}$ and 37 (10.5\%) were

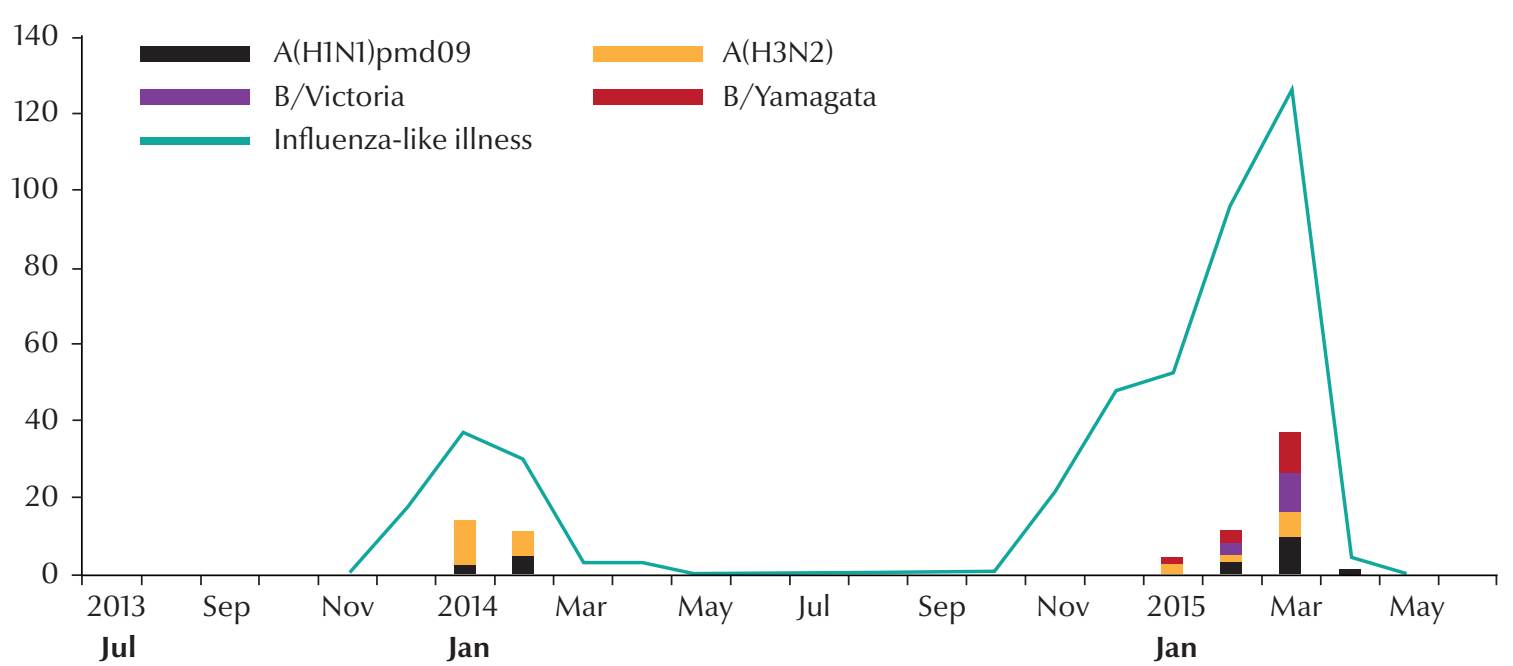

Figure 1 Epidemiology curve of acute respiratory infections and influenza in Lebanon 


\begin{tabular}{|c|c|c|c|c|c|c|}
\hline Type/Subtype & $\begin{array}{l}\text { No. } \\
\text { tested }\end{array}$ & $\begin{array}{c}\text { Oseltamivir } \\
\mathrm{IC}_{50}(\mathrm{SD})(\mathrm{nM})\end{array}$ & $\begin{array}{c}\text { Zanamivir } \\
\mathrm{IC}_{50}(\mathrm{SD})(\mathrm{nM})\end{array}$ & $\begin{array}{c}\text { Peramivir } \\
\mathrm{IC}_{50}(\mathrm{SD})(\mathrm{nM})\end{array}$ & $\begin{array}{l}\text { Laninamivir } \\
\mathrm{IC}_{50}(\mathrm{SD})(\mathrm{nM})\end{array}$ & Resistance \% \\
\hline \multicolumn{7}{|l|}{$2013 / 14$ season } \\
\hline $\mathrm{A}(\mathrm{H} 1 \mathrm{N1}) \mathrm{pdm} 09$ & 3 & $0.87 \pm 0.07$ & $0.49 \pm 0.03$ & $0.11 \pm 0.01$ & $0.45 \pm 0.01$ & 0 \\
\hline $\mathrm{A}(\mathrm{H} 3 \mathrm{~N} 2)$ & 6 & $0.7 \pm 0.08$ & $0.73 \pm 0.21$ & $0.11 \pm 0.01$ & $0.72 \pm 0.13$ & 0 \\
\hline \multicolumn{7}{|l|}{$2014 / 15$ season } \\
\hline A(H1N1pdm)09 & 6 & $1.20 \pm 0.16$ & $0.54 \pm 0.05$ & $0.12 \pm 0.01$ & $0.43 \pm 0.05$ & 0 \\
\hline $\mathrm{A}(\mathrm{H} 3 \mathrm{~N} 2)$ & 3 & $1.20 \pm 0.16$ & $0.62 \pm 0.13$ & $0.15 \pm 0.03$ & $0.87 \pm 0.09$ & 0 \\
\hline B & 8 & $1.20 \pm 0.16$ & $13.57 \pm 5.25$ & $1.10 \pm 0.27$ & $5.56 \pm 1.67$ & 0 \\
\hline
\end{tabular}

$S D=$ standard deviation .

influenza B. Real-time PCR analysis showed that 17 (19.3\%) were $\mathrm{A}(\mathrm{H} 1 \mathrm{N1})$ pdm09, 10 (11.3\%) were $\mathrm{A}(\mathrm{H} 3 \mathrm{~N} 2), 13$ (14.7\%) were B/Victoria, and 16 (18.8\%) were B/Yamagata by (8). Therefore, 64-81\% of the RDT-positive samples were detectable by PCR.

None of the $\mathrm{A}(\mathrm{H} 1 \mathrm{Nl})$ pdm09 viruses possessed the $\mathrm{H} 275 \mathrm{Y}$ mutation. All of the influenza isolates were susceptible to the 4 neuraminidase inhibitors tested (Table 1). The IC50 values of peramivir and laninamivir against influenza $B$ isolates were much lower than those for oseltamivir and zanamivir.

Phylogenetic analysis of the HA gene showed that the Lebanese $\mathrm{A}(\mathrm{H} 1 \mathrm{~N} 1)$ pdm09 isolates belonged to clade 6B, which is characterized by mutations K163Q, A256T, and K283E (Figure 2). Five isolates from the 2014/15 season formed a sub-cluster that was defined by the N38D and K142R amino acid substitutions. In the case of $\mathrm{A}(\mathrm{H} 3 \mathrm{~N} 2)$, the isolates from the 2013/14 season belonged to subclade 3C.3, which is defined by the T128A amino acid substitution (Figure 2). The 2014/15 Lebanese $A(H 3 N 2)$ isolates fell into the 3C.2 subclade, characterized by an N144S mutation. Lebanese influenza B isolates from the 2014/2015 season belonged to genetic groups 3 of the $\mathrm{B} /$ Yamagata-lineage and $\mathrm{A}$ of the $\mathrm{B} /$ Victoria lineage (Figure 2).

\section{Discussion}

We demonstrated that influenza viruses from the 2013/14 and 2014/15 seasons remain largely susceptible to neuraminidase inhibitors; this is consistent with the findings of other studies (12-15). Influenza A(H1N1) pmd09 was the most prevalent subtype circulating during the 2013/14 season, while influenza B was not detected. In contrast, influenza B was predominant in the 2014/15 season. In this study, 64-81\% of the RDT-positive samples were detectable by PCR. However, other data from our laboratory (unpublished data, 2015) indicate that for the RDT test used in our study, specificity is $>99 \%$. The discrepant results between RDT and PCR results may have been a result of deterioration of the specimens during storage at the clinic or during transfer to the laboratory. Overall, our results emphasize on the clinical value of point-of-care RDT as it provides an easily accessible diagnostic tool enabling clinicians to make immediate decisions on whether to prescribe antivirals to their patients.

The phylogenetic analysis revealed that influenza outbreaks in Lebanon are seeded through introductions of multiple strains within the same season. Our ability to track the origins of influenza outbreaks in Lebanon and their movement across the region was limited by the lack of influenza sequences from most of the Middle Eastern countries, especially those neighbouring Lebanon. Our database search of influenza virus sequences from countries neighbouring Lebanon returned very few results, an indication of the large gaps in influenza surveillance in this highly interconnected region. A full understanding of the dynamics of influenza in Lebanon and the region will require better monitoring of influenza outbreaks and sequencing of the viruses isolated in these countries. The Middle East region is facing numerous wars and conflicts that have displaced millions of people within and across borders causing many people to be out of reach of the health system. At the time of our study, Lebanon was hosting more than 1.5 million Syrian refugees (one third of the overall population), many of whom were living in substandard shelters and were thus out of reach of surveillance activities (16). Further studies are urgently needed to assess the burden of respiratory infections among refugees and how they affect the disease dynamics among the local population.

\section{Acknowledgements}

Funding: This study was funded by a seed fund from the Faculty of Medicine, American University of Beirut (HZ), the Center for Infectious Diseases Research (GD), JSPS Core-to-Core Program, B, Asia-Africa Science Platforms, and Kakenhi (Grants-in-Aid for Scientific Research), and Japan Initiative for Global Research Network (J-GRID) (RS). All Japanese grants were sourced from the Ministry of Education, Culture, Sports, Science and Technology (MEXT), Japan.

Competing interests: None Declared 
m
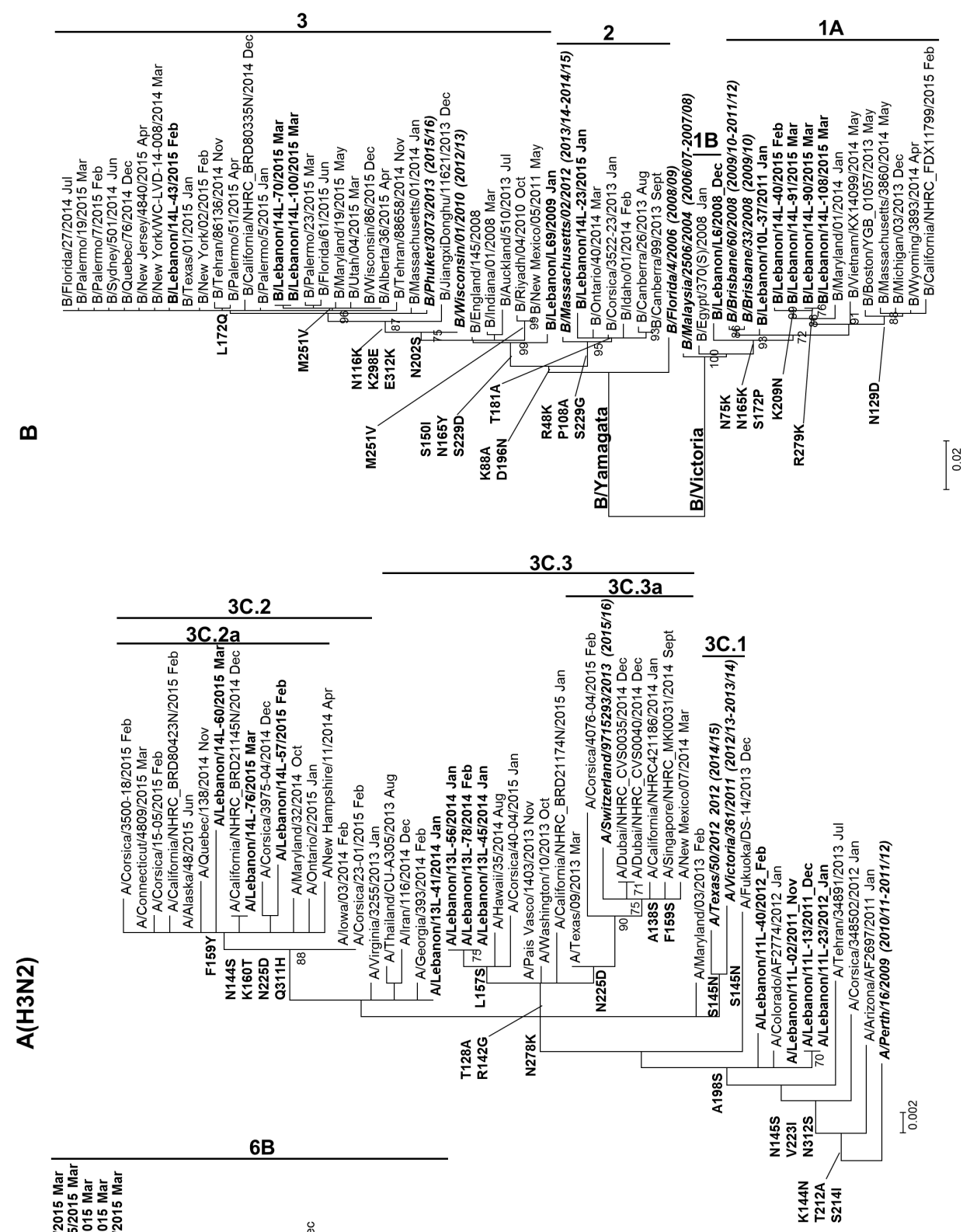

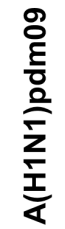
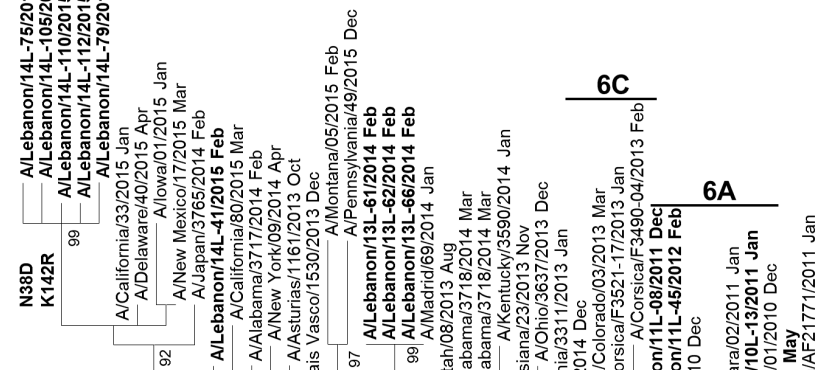

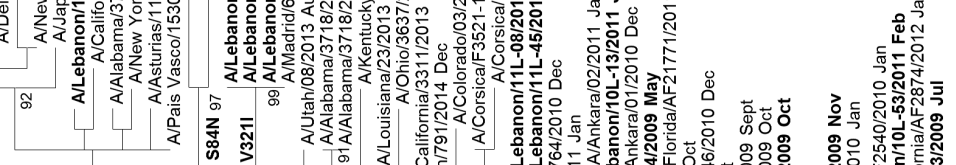
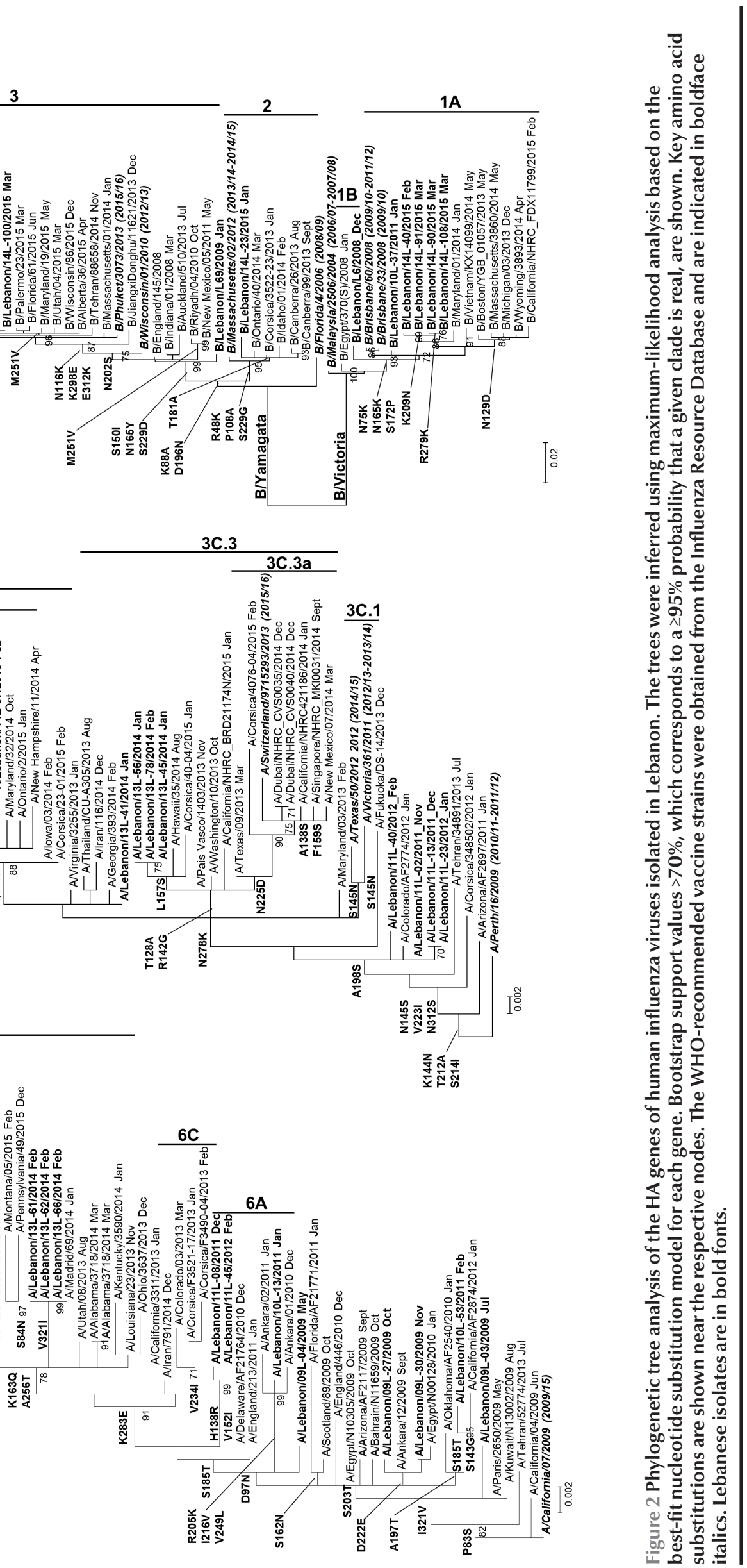


\section{References}

1. Nair H, Brooks WA, Katz M, Roca A, BerkleyJA, Madhi SA, et al. Global burden of respiratory infections due to seasonal influenza in young children: a systematic review and meta-analysis. Lancet. 2011;378:1917-30.

2. Belshe RB. The need for quadrivalent vaccine against seasonal influenza. Vaccine. 2010;28 Suppl. 4:D45-53.

3. Nelson MI, Holmes EC. The evolution of epidemic influenza. Nat Rev Genet. 2007;8:196-205.

4. Cox NJ, Subbarao K. Global Epidemiology of influenza: past and present. Annu Rev Med. 2000;51:407-21.

5. Jefferson T, Jones MA, Doshi P, Del Mar CB, Hama R, Thompson MJ, et al. Neuraminidase inhibitors for preventing and treating influenza in adults and children (update). Cochrane Database Syst Rev. 2014;21(3):217-21 (http://onlinelibrary. wiley.com/doi/10.1002/14651858.CD008965.pub4/abstract, accessed 28 Sptember 2016).

6. Dapat IC, Dapat C, Baranovich T, Suzuki Y, Kondo H, Shobugawa $Y$, et al. Genetic characterization of human influenza viruses in the pandemic (2009-2010) and post-pandemic (2010-2011) periods in Japan. PLoS One. 2012;7:e36455.

7. Hurt AC, Barr IG, Hartel G, Hampson AW. Susceptibility of human influenza viruses from Australasia and South East Asia to the neuraminidase inhibitors zanamivir and oseltamivir. Antiviral Res. 2004;62:37-45.

8. Dapat C, Kondo H, Dapat IC, Baranovich T, Suzuki Y, Shobugawa $Y$, et al. Neuraminidase inhibitor susceptibility profile of pandemic and seasonal influenza viruses during the 20092010 and 2010-2011 influenza seasons in Japan. Antiviral Res. 2013;99:261-9.

9. Dapat C, Saito R, Kyaw Y, Naito M, Hasegawa G, Suzuki Y, et al. Epidemiology of Human Influenza A and B Viruses in Myanmar from 2005 to 2007. Intervirology. 2009;52:310-20.
10. Hall T. BioEdit: a user-friendly biological sequence alignment editor and analysis program for Windows 95/98/NT. Nucleic Acids Symp Ser. 1999;41:95-8.

11. Tamura K, Stecher G, Peterson D, Filipski A, Kumar S. MEGA6: Molecular Evolutionary Genetics Analysis Version 6.0. Mol Biol Evol. 2013;30:2725-9.

12. Ikematsu H, Kawai N, Iwaki N, Kashiwagi S. In vitro neuraminidase inhibitory activity of four neuraminidase inhibitors against clinical isolates of the influenza virus circulating in the Japanese 2013-2014 season. J Infect Chemother. [Internet] 2015 (http://www.sciencedirect.com/science/article/pii/ S1341321X15001245, accessed 7 July 2016).

13. Influenza virus characterisation: summary Europe [Internet]. Solna, Sweden: European Centre for Disease Prevention and Control; 2015 [cited 2016 Apr 6]. (http://ecdc.europa.eu/en/ publications/Publications/influenza-virus-characterisationseptember-2015.pdf. accessed 6 April 2016).

14. Influenza virus characterisation: summary Europe [Internet]. Solna, Sweden: European Centre for Disease Prevention and Control; 2014 (http://ecdc.europa.eu/en/publications/Publications/influenza-virus-characterisation-september-2015. pdf, accessed 6 April 2016).

15. Ikematsu H, Kawai N, Iwaki N, Kashiwagi S. In vitro neuraminidase inhibitory activity of four neuraminidase inhibitors against influenza virus isolates in the 2011-2012 season in Japan. J Infect Chemother Off J Jpn Soc Chemother. 2014;20:77-80.

16. 3RP 2016 Mid-year report. 3RP Regional Refugee and Resilience Plan 2016-2017 in response to the Syria Crisis [Internet]. Amman: UNHCR; 2016 (http://www.3rpsyriacrisis.org/, accessed 5 September 2016). 